\title{
A Comparison of International Residential Housing Risk Premia ${ }^{\dagger}$
}

\author{
Chris Julliard \\ London School of Economics \\ and \\ Grace Wong \\ Wharton School of Business
}

Preliminary Version: For Discussion and Criticism Only

\footnotetext{
${ }^{\dagger}$ Yijia Gu and Alexandra Infeld provided excellent research assistance. Corresponding author: Grace Wong, 1400 SH-DH, 3620 Locust Walk, Philadelphia, PA 19104-6302 +(215) 5737903 wongg@,wharton.upenn.edu
} 


\section{Introduction}

Early literature suggests substantial risk-adjusted returns to real estate.

(Brueggman, Chen and Thibodeau, Ibbotson and Sielgel, Hartzell, Hekman and Miles)

Chan, Hendershott and Sanders (1990), using returns to U.S.-listed equity REITs, show

that the real estate risk premium is likely to be caused by the usage of smoothed, appraisal housing price data which understates the volatility of returns. This paper contributes to this debate by first constructing a panel of housing risk premia for 13 developed countries over a long sample period (1966:Q3 to 2004:Q4), and then exploring the relationship of these risk premia to changes in the financial market depth, equity market activities, property tax system, urbanization and development or zoning regulations. ${ }^{1}$ By comparing the experiences of housing markets in various developed countries, this paper adds to our understanding of what constitutes the real estate risk premium.

Compared to the returns to equity, real estate returns are relatively little studied. One obstacle is the lack of reliable transaction data. International comparisons are particularly scarce because of data limitation outside the United States. The drawback of time series studies of asset returns, however, is their lack of power to distinguish among various macroeconomic developments that may have significant co-movements. We fill in this gap in the literature by exploiting a rich data set and by focusing on panel analyses.

\footnotetext{
${ }^{1}$ Thirteen OECD countries are studied: Australia, Canada, Denmark, France, Italy, Japan, the Netherlands, Norway, Spain, Sweden, Switzerland, United Kingdom and the United States. Germany is omitted from the preliminary results presented because of the limited availability of consistent data throughout the sample period.
} 


\section{Estimating the Housing Risk Premia}

\section{A. On the Stationarity of the Price-rent Ratio}

In principle, an agent could either buy or rent a house to receive the same service flow. However, renting and buying a house are not perfect substitutes since households might derive extra utility from owning a house (e.g. ability to customize the interior, pride of ownership). Moreover, properties for rent might on average be different from properties for sale. ${ }^{2}$ Nevertheless, long-run movement in the rent level should capture long-run movements in the service flow. Also, Gallin (2004) finds that house prices and rents are co-integrated (i.e. stationary) and that the price-rent ratio is a good predictor of future price and rent changes. ${ }^{3}$ Finally, focusing on the price-rent ratio is analogous to the commonly used price-dividend ratio to analyze the stock market.

Denote with $P$ and $L$ respectively the price and rent of housing. Disregarding taxes and depreciation, the standard asset pricing relation among these variables will be

$$
P_{t}=E_{t}\left[m_{t, t+1}\left(P_{t+1}+L_{t+1}\right)\right]
$$

where $m_{t, t+1}$ is the stochastic discount factor between $t$ and $t+1 .{ }^{4}$ Iterating forward we have

$$
P_{t}=E_{t}\left[\sum_{s=1}^{\infty} m_{t, t+s} L_{t+s}\right]+E_{t}\left[\lim _{T \rightarrow \infty} m_{t, t+T} P_{t+T}\right]
$$

\footnotetext{
${ }^{2}$ The house price index reflects all types of dwellings while rents tend to overweight smaller and lower quality dwellings. Given that high quality houses fluctuate more over the business cycle, we would have to control for business cycle patterns in the empirical analysis.

3 Note that Gallin (2003) empirically rejects the hypothesis of co-integration between prices and income using panel-data tests for co-integration, that have been shown to be more powerful than the timeseries analog. This implies that the commonly used error correction representation of prices and income would lead to erroneous frequentist inference.

${ }^{4}$ For example, in the textbook C-CAPM we would have

$$
m_{t, t+1}=\beta \frac{u^{\prime}\left(C_{t+1}\right)}{u^{\prime}\left(C_{t}\right)} \cong \beta\left(1-\gamma \Delta \ln C_{t+1}\right)
$$
}

where $\gamma$ is the relative risk aversion coefficient and $0<\beta<1$ is the inter-temporal discount factor. 


$$
=E_{t}\left[\sum_{s=1}^{\infty} m_{t, t+s} L_{t+s}\right]
$$

where we assumed that the last term goes to zero in expectation (this transversality condition basically rules out explosive bubble paths for the price level). Dividing both sides by $L_{t}$, we have ${ }^{5}$

$$
\frac{P_{t}}{L_{t}}=E_{t}\left[\sum_{s+1}^{\infty} m_{t, t+s} \frac{L_{t+s}}{L_{t}}\right]=E_{t}\left[\sum_{s=1}^{\infty} \prod_{j=0}^{s-1} m_{t+j, t+j+1} \frac{L_{t+j+1}}{L_{t+j}}\right] .
$$

This last expression gives two important messages. First, under very mild regularity conditions, ${ }^{6}$ the price-rent ratio will be stationary, justifying on a theoretical ground the empirical findings of Gallin (2004). Second, the price rent ratio is the discounted sum of future rent growth rates and carries information regarding both the future expected rent growth and, most importantly, the implied discount factor that will be the focus of our analysis. In the next section we push this intuition even further to back up the

${ }^{5}$ Note that here I am using the fact that

$$
m_{t, t+s}=\prod_{j=0}^{s-1} m_{t+j, t+j+1}
$$

${ }^{6}$ For example, in the textbook C-CAPM we would have

$$
\frac{P_{t}}{L} \cong E_{t}\left[\sum_{s=1}^{\infty} \beta^{s} \prod_{j=1}^{s}\left(1-\gamma \Delta \ln C_{t+j}\right) \frac{L_{t+j}}{L_{t+j-1}}\right]
$$

implying that the stationarity of consumption and rent growth rates and the assumption of both series having finite second moments would be enough to deliver a stationary price rent ratio.

To see this in another way, note that in a world in which rent follows a deterministic path we would have

$$
\frac{P_{t}}{L}=\sum_{s=1}^{\infty} \beta^{s} \prod_{j=0}^{s-1} \frac{1}{R_{t+1+j}^{f}} \frac{L_{t+j+1}}{L_{t+j}}
$$

where $R_{t+1}^{f}$ is the gross risk free rate between $t$ and $t+1$ and I used the fact that $E_{t}\left[m_{t, t+1}\right]=\frac{1}{R_{t+1}^{f}}$ 
(unobserved) required rate of return on housing investment from the observable price rent ratios and rent growth rates.

\section{B. Implied Expected Returns}

The gross return on housing, $R_{h}$, is given by the following accounting identity

$$
R_{h, t+1}=\frac{P_{t+1}+L_{t+1}}{P_{t}}
$$

Following Campbell and Shiller (1988), we log-linearize this relation around the steady state. Under the assumption that the price-rent ratio is stationary, we can log-linearize the last equation as

$$
r_{h, t+1}=(1-\rho) k+\rho\left(p_{t+1}-l_{t+1}\right)-\left(p_{t}-l_{t}\right)+\Delta l_{t+1}
$$

where $r_{h, t}:=\log R_{h, t}, p_{t}:=\log P_{t}, l_{t}:=\log L_{t}, \Delta l_{t}:=l_{t}-l_{t-1}, \rho:=1 /(1+\exp (\overline{l-p}))$,

$\overline{l-p}$ is the long run average log rent-price ratio, and $k$ is a constant. The log price-rent ratio can be therefore rewritten (disregarding a constant term) as a linear combination of future rent growth, future returns on housing and a terminal value

$$
p_{t}-l_{t}=\lim _{T \rightarrow \infty}\left[\sum_{r=0}^{T} \rho^{T}\left(\Delta l_{t+r+1}-r_{h, t+r+1}\right)+\rho^{T}\left(p_{t+T}-l_{t+T}\right)\right]
$$

Moving to excess rent growth rates, $\Delta l_{t+T}^{e}=\Delta l_{t}-r_{t}$, and excess returns (risk premia) on housing, $r_{h, t}^{e}=r_{h, t}-r_{t}$, where $r_{t}$ is the log real risk free rate, the price-rent ratio can be expressed as

$$
p_{t}-l_{t}=\sum_{r=0}^{\infty} \rho^{r}\left[\Delta l_{t+r+1}^{e}-r_{h, t+r+1}^{e}\right]+\lim _{T \leftarrow \infty} \rho^{T}\left(p_{t+T}-l_{t+T}\right)
$$


This equality has to hold ex-post for any realization and hence, holds ex-ante in expectation for any probability measure that is

$$
p_{t}-l_{t}=\sum_{r=0}^{\infty} \rho^{r} E_{t}\left[\Delta l_{t+r+1}^{e}-r_{h, t+r+1}^{e}\right]+E_{t}\left[\lim _{T \leftarrow \infty} \rho^{T}\left(p_{t+T}-l_{t+T}\right)\right]
$$

Assuming that the transversality condition holds (i.e. ruling out the presence of intrinsic bubbles7) we have

$$
p_{t}-l_{t}=\sum_{r=0}^{\infty} \rho^{r} E_{t}\left[\Delta l_{t+r+1}^{e}-r_{h, t+r+1}^{e}\right]
$$

This last expression has a straightforward economic interpretation: if the price-rent ratio is high toady, agents either expect high future rent growth rates or lower future discount rates.

More importantly the last expression can be re-arranged to express the market expectation of housing risk premia as a function of the price rent ratio and expected rent growth rates

$$
\sum_{r=0}^{\infty} \rho^{r} E_{t} r_{h, t+r+1}^{e}=\sum_{r=0}^{\infty} \rho^{r} E_{t} \Delta l_{t+r+1}^{e}-\left(p_{t}-l_{t}\right)
$$

Therefore, we can back up time variation in risk premia from the time variation in rent growth rates and the price rent ratio. In particular, defining with $\hat{E}_{t} \Delta l_{t+r}^{e}$ the consistent estimate of the expected rent growth in period $t+r$ conditional on the information available at time t, we can estimate the future discounted stream of risk premia (let it be denoted by $\left.\hat{r}_{h, t}^{e}\right)$ as

\footnotetext{
${ }^{7}$ See Froot and Obstfeld (1991).
} 


$$
\hat{r}_{h, t}^{e}:=\sum_{r=0}^{\infty} \rho^{r} \hat{E}_{t} \Delta l_{t+r+1}^{e}-\left(p_{t}-l_{t}\right)
$$

Moreover, we can identify the time $t+1$ innovation in risk premia (let it be denoted by $\left.\widetilde{r}_{h, t+1}^{e}\right)$ as

$$
\widetilde{r}_{h, t+1}^{e}:=\left(\hat{E}_{t+1}-\hat{E}_{t}\right) \hat{r}_{h, t}^{e}=\left(\hat{E}_{t+1}-\hat{E}_{t}\right) \sum_{r=0}^{\infty} \rho^{r} \Delta l_{t+r+1}^{e}-\Delta\left(p_{t+1}-l_{t+1}\right) .
$$

\section{Empirical Implementation}

To construct $\hat{r}_{h, t}^{e}$ and $\widetilde{r}_{h, t}^{e}$, we follow Campbell (1991) and compute the objective expectations of rent growth rates using a reduced form VAR.

Consider the $\mathrm{VAR}^{8}$

$$
z_{t+1}=A z_{t}+\varepsilon_{t+1}
$$

where $z_{t}$ is a $n \times 1$ vector of time series and $A$ is a $n \times n$ matrix of coefficients. Without loss of generality, assume that $\Delta l_{t}^{e}$ is the first variable included in $z_{t}$ and let $e_{1}$ be a $n \times 1$ vector that has entry 1 for the first element and zeros elsewhere. Denoting with $\hat{E}_{t}$, the VAR forecast operator conditional on the information set available at time $t$ (basically we proxy rational expectations with linear projections in the spirit of Sims), we have that

$$
\begin{aligned}
\hat{E}_{t} z_{t+r} & =\hat{A}^{r} z_{t} \rightarrow \hat{E}_{t} \Delta l_{t+r+1}^{e}=e_{1}^{\prime}\left[A^{r} z_{t}\right] \\
\left(\hat{E}_{t+1}-\hat{E}_{t}\right) z_{t+1} & =\hat{\varepsilon}_{t+1} \rightarrow\left(\hat{E}_{t+1}-\hat{E}_{t}\right) \Delta l_{t+r+1}^{e}=e_{1}^{\prime}\left\lfloor\hat{A}^{r} \hat{\varepsilon}_{t+1}\right\rfloor
\end{aligned}
$$

where $\hat{A}$ are the VAR estimated coefficients and $\hat{\varepsilon}$ are the estimated residuals.

Therefore

$$
\hat{r}_{h, t}^{e}=\sum_{r=0}^{\infty} \rho^{r} e_{1}^{\prime}\left[\hat{A}^{r+1} z_{t}\right]-\left(p_{t}-l_{t}\right)
$$

\footnotetext{
${ }^{8}$ This is without loss of generality since a VAR with $m$ lags can always be rewritten in an auto-regressive form of order one.
} 


$$
\widetilde{r}_{h, t+1}^{e}=e_{1}^{\prime}(I-\rho \hat{A})^{-1} \hat{\varepsilon}_{t+1}-\Delta\left(p_{t+1}-l_{t+1}\right)
$$

that is, in each period we can estimate (up to a constant) expected future risk premia and innovations to risk premia as a function of observable variables. The variables included in our estimation are GDP growth rate, inflation-adjusted risk-free interest rate, log housing price-rent ratio, and rent growth rate.

Moreover, note that since $\left(p_{t}-l_{t}\right)=\log \left(P_{t} / L_{t}\right)$, and that our identification is exact up to a constant, we have that to implement this approach empirically we need to know the $\log$ price rent ratio only up to a constant i.e. we only need house price indexes and rental prices indexes while the exact level of $P_{t} / L_{t}$ is not necessary (that is, we need the indexes to only tract the time variation in rent and prices).

\section{Data Description}

The variables included in our estimation are GDP growth rate, inflation-adjusted risk-free interest rate, log housing price-rent ratio, rent growth rate and a business cycle. See Brunnermeier and Julliard

\section{Explaining the Housing Risk Premia}

To investigate the variations of $\hat{r}_{h, t}^{e}$ above, the following regression is performed:

$$
\mathrm{R}_{\mathrm{ht}}=\alpha+\beta \mathrm{X}_{\mathrm{ht}}+\mathrm{C}_{\mathrm{h}}+\text { Year }_{\mathrm{t}}+\text { Quarter }_{\mathrm{t}}+\varepsilon_{\mathrm{ht}}
$$

where $\mathrm{R}_{\mathrm{ht}}$ is the demeaned excess returns $\left(\hat{r}_{h, t}^{e}\right)$ for country $h$ at time $t . \mathrm{X}_{\mathrm{ht}}$ are time-varying, country-specific measures related to development of financial and equity markets, the property tax system, urbanization and zoning regulations which are described in detail below. $\mathrm{C}_{\mathrm{h}}$ captures any country-specific, non-time-varying factors, which include but are not limited to initial conditions at the start of the sample period, 
types of judiciary system and geographical location. ${ }^{9}$ The combined explanatory power of these three groups of fixed effects is relatively low (R-squared $=0.07)$. To account for potential serial correlation in $\varepsilon_{\mathrm{ht}}$, Newey-West standard errors are reported. Two versions of equation (1) are shown throughout this paper, with and without the year and quarter fixed effects.

A comprehensive panel data set was compiled to measure developments in the financial markets, equity markets, demographics and related institutions. Here we discuss correlations between the estimated risk premia and factors that are robust to reasonable changes in specification and variable definitions. Other results are available upon request. Table 1 shows the summary statistics of all variables in the regressions presented.

\section{A. Debt and Equity Markets}

CHECK Christian Gollier paper in MIT book about multiple risks.

It is not surprising that the size of the banking sector (relative to GDP), which reflects the depth and sophistication of the credit market, has a negative correlation with the housing premia (columns $1 \mathrm{ad} 2$ ). The ease to obtain credit is likely to reduce expected risk. On the other hand, two measures of stockmarket liquidity - total valued traded as a ratio of GDP and the turnover ratio - show a positive relationship with the housing risk premia, which is somewhat surprising (columns 3 to 6 ). Two other measures of stockmarket development, the ratio of stockmarket capitalization to GDP and the ratio of total equity issues to GDP, do not have statistically significant correlations with the housing premia.

\footnotetext{
${ }^{9}$ With the exception of Australia, which joined the OECD in 1971, all other countries in our sample were original member countries. A dummy controlling for the accession date is not significant in any of the specifications showed in this paper.
} 
One noteworthy result in Table 2 is how stable and robust the correlations between risk premia and measures of debt and equity market developments are. Although there exists a positive correlation between the debt and equity market indicators $(=0.527)$, their relationships to the housing premia seem to be more or less independent, as shown in columns 7 to 10 . It is also worthwhile to point out that none of the other variables explored below has similar explanatory power.

\section{B. Institutions and Demographics}

In all results that follow, we control for the log ratio of deposit money bank assets to GDP and the log ratio of stockmarket total value traded to GDP. Results using log stockmarket turnover ratio are very similar (Tables 3A and 4A).

The ratio of federal to local total property tax revenues, which proxies for how centralized the tax system is concerning real estate, is positively correlated with risk premia (columns 1 and 2, Table 3). This is consistent with the existing literature on how decentralization promotes efficiency.

Another institutional difference we investigate is the maximum loan-to-value (LTV) ratio. ${ }^{10}$ Although the maximum LTV ratio does not show much variation over time within each country, it has a stable and negative relationship with housing risk premia (columns 3 and 4). A higher LTV ratio presumably helps form a more substantial and stable source of housing demand. We expect this impact to differentiate by income growth - given the same change in the maximum LTV ratio, the higher the income growth the larger (in absolute value) its impact should be. While columns 5 to 8 do show a negative and significant interaction term (between GDP growth and the maximum LTV

\footnotetext{
${ }^{10}$ Data on maximum LTV ratios are obtained from Table 2 in Almeida, Campello and Liu (working paper, 2006).
} 
ratio), the main effect becomes less significant and positive. This might be due to the lack of statistical power to identify the precise impact of a factor with limited time variation within countries.

The last two columns explore one dimension of demographics - urban population growth. It is unclear how this might impact the housing risk premia: while urbanization might imply housing demand growth, it might also indicate rapid demographic changes that introduce uncertainty to the market. Our data show that a higher rate of urban population growth seems to correlate with a higher housing premia.

Comparing Tables 2 and 3, measures of debt and equity markets have reasonably stable and generally robust correlations with the housing risk premia.

\section{Developmental or Zoning Regulations}

While we acknowledge the difficulty to meaningfully measure zoning changes at a national level, we attempt to capture and explore major changes in each of these countries. We searched throughout government publications, zoning manuals, legal references and real estate building guides and came up with a list of regulations that took effect during our sample period.

Three types of regulations stand out. "Decentralization" refers to when the zoning or building application process is more decentralized, typically introducing a higher degree of variation in terms of zoning restrictiveness within the country. Changes with a "Social" focus mostly concern either participation of the general public or the right of current residents to restrict development on environmental grounds. A third type includes "Simplification" or streamlining of the zoning application process. The rest we have at the moment grouped under "Others", which deserve further study. 
Columns 1 and 2 show several interesting results. Housing risk premium increases with more decentralization or social focus in the zoning process. This is perhaps not surprising because it is more costly to learn how to deal with a system that varies from place to place within the country. Similarly, more community participation implies a more complex game with players with different objectives. In column 1 the two coefficients do not significantly differ from each other, therefore we experiment with a combined measure which is the simple addition of the two indicators, which produces results which are remarkably similar (columns 3 and 4). Coefficients of the unclassified ("Others") regulations are significant and negative in all specifications.

It is puzzling that efforts to simplify the system do not seem to have any significant impact on the housing premium. We have omitted this group for columns 5 to 8 , which do not change our previous conclusions.

\section{Conclusion}

The power of this paper derives from our ability to control for country-level fixed effects, which absorbs the impact of initial conditions and other non-time-varying factors, and investigate significant factors that commonly impact the evolution of the housing risk premium in different markets.

We have identified important roles that financial market development and various institutions play, some of which demand further and a more detailed study. These include liquidity in the equity market and different types of zoning.

An international comparison not only allows us to explore the universality of relationships between economic quantities, but it is also timely for the increasingly integrated global economy. Traditionally real estate is one of the major assets which lacks 
international arbitrage, but with the development of various investment vehicles, the increased flow of global capital and liberalization of local property laws, we are seeing more foreign ownership and development of real estate in many countries. It is indeed logical to draw lessons from different markets by exploring the possibilities of a common, underlying market mechanism. 


\section{References}

Campbell, J. Y. (1991): .A Variance Decomposition for Stock Returns,.Economic Journal, 101, 157.79 .

Campbell, J. Y., and R. J. Shiller (1988): .The Dividend-Price Ratio and Expectations of Future Dividends and Discount Factors,.Review of Financial Studies, 1(3), 195.228.

Froot, K. A., and M. Obstfeld (1991): .Intrinsic Bubbles: The Case of Stock Prices,.American Economic Review, 81(5), 1189.1214.

Gallin, J. (2003): .The Long-Run Relationship between House Prices and Income: Evidence from Local Housing Markets,.Board of Governors of the Federal Reserve Discussion Paper 2003-17.

(2004): .The Long-Run Relationship between House Prices and Rents,.Board of Governors of the Federal Reserve Discussion Paper 2004-50. 